\title{
De la otredad a la praxis liberadora: la construcción de métodos para la conciencia
}

\author{
From otherness to liberating praxis: The construction \\ of methods for consciousness
}

Maritza MONTERO ${ }^{1}$

\section{Resumen}

En esta conferencia se presentan las bases analécticas de las formas de producir en la praxis cambios conducentes a la concientización: esto es, a la transformación de la conciencia en cuanto a formas consideradas como modos únicos y cotidianos de producir la vida social. En tal sentido, se definen y analizan cuatro modos que son parte de la vida cotidiana: la habituación y la naturalización, así como la ideologización y la alienación, cuyas bases se afirman en los primeros modos citados. Asimismo se presentan las características del método analéctico construidas en la praxis, indicando la posibilidad de aplicar la acción a otros modos de interpretar la vida cotidiana, igualmente alienadores.

Palabras-clave: Alienación; Habituación; Ideología; Psicología comunitaria.

\begin{abstract}
In this conference, we present the analectical methods of the ways to produce, in praxis, forceful changes to consciousness: that is to say, the transformation of the conscious in regards to, for example, the unique and everyday manners of producing social situations. In this sense, four ways, each part of everyday life, are defined and analysed: habituation and naturalization, as well as ideologization and alienation, whose basis is affirmed in the first ways mentioned above. At the same time, the characteristics of the analectical method are presented, built in praxis, indicating the possibility of applying the actions to other ways of interpreting everyday life, which are equally alienating.
\end{abstract}

Keywords: Alienation; Habituacion; Ideology; Community psychology.

Entre la Psicología Comunitaria (PC) y la Psicología de la Liberación (PL) hay una relación de construcción de teoría y prácticas que hasta ahora ha sido muy provechosa. La PC fue quizás la primera rama de la Psicología en acoger las ideas liberadoras, no sólo por la relación que en América Latina han tenido muchas psicólogas y psicólogos, con ambas ramas de la Psicología, sino además porque, en América Latina, la PC se comienza a desarrollar tardíamente (si la comparamos con Canadá o con los Estados Unidos de América en la segunda mitad de los 60). En nuestro caso eso no ocurrió como un

$\checkmark \nabla \nabla$

1 Universidad Central de Venezuela, Facultad de Humanidades y Educación, Consejo Académico del Doctorado en Psicología. Av. Los Ilustres, Ciudad Universitaria, Código Postal 1051, Los Chaguaramos, Caracas, Venezuela. E-mail: <mmonteroster@gmail.com>. 
acto especular de imitación o de seguimiento - como lo que se estaba haciendo en esas regiones del mundo -, sino como una reacción crítica a la psicología social que se practicaba en nuestros países que, como lo he señalado muchas veces, no permitía trabajar con aquellos que más necesitaban servicios psicosociales y que menos los recibían. Los resultados obtenidos por nuestra ciencia no llegaban a las capas más pobres y más necesitadas, y su divulgación solo ocurría en pocas revistas científicas cuyos lectores no eran particularmente abundantes.

La Psicología Comunitaria basada en la participación, que trabaja no con sujetos de investigación, sino con personas con nombre y apellido, de lugares cuya dirección se conoce y produciendo efectos visibles; la que había leído a Freire, a Fals Borda, a Marx y a los postmarxistas de las Escuelas de Praga, Budapest, de Frankfurt y de Paris, no para repetir, sino para discutir, hizo una rápida relación con la idea que en 1986 Ignacio Martín Baró (IMB) planteó desde El Salvador y que, después de su trágica muerte en 1989, ha sido desarrollada por numerosos psicólogos en nuestro Continente, así como en África, Europa, Oceanía y Asia. IMB propuso la creación de una PL, cuyo asesinato le impidió desarrollar. Ese desarrollo ha venido haciéndose desde fines de los 1980 y ha incorporado no sólo las ideas freireanas, sino las producidas en la Filosofía de la Liberación por Enrique Dussel y también otras provenientes de la teología de liberación, movimientos ambos generados en nuestra América.

En el proceso de construcción de una PL, la PC ha sido no sólo pionera sino además ha contribuido con la creación de métodos desarrollados a partir de las ideas de Dussel, así como de ideas desarrolladas en la práctica participativa. La problematización y la concientización (ideas freireanas) son un ejemplo. En la PC no se trata solo de palabras, sino de formas de praxis, es decir, de práctica que genera teoría y teoría que genera práctica. Lo que busca la PC es producir transformaciones realizadas en comunidad por quienes son parte de ella y por psicólogos/as que trabajan conjuntamente con esas personas. Se trata 142 de hacer, de transformar con el Otro, incluyendo las acciones de transformación que parten de ese Otro y su necesidad. Acciones que van desde la palabra que hace hasta los hechos apalabrados.

\section{Qué es la Otredad, quién es el Otro}

Esto nos lleva a definir quién es el Otro y qué es la Otredad, ese lugar y sentido que se considera como propio del Otro y que Levinas (1970/ 1995, p.60) ha definido como: "La alteridad, la heterogeneidad radical de lo Otro solo es posible si lo Otro es otro con relación a un término cuya esencia es permanecer como en el punto de partida. Servir de entrada a la relación, ser el Mismo no relativamente, sino absolutamente". Nuestro concepto de otredad se origina de allí y de la filosofía de la liberación latinoamericana. En breves palabras presentaré una definición generada a partir de la obra "Totalidad e Infinito", de Levinas (1970/1995), quien presenta las bases de lo que hoy orienta nuestra psicología de la liberación y quien también influyó en los dos filósofos latinoamericanos que han construido la Filosofía de la Liberación que se utiliza hoy en el mundo: Juan Carlos Scannone y Enrique Dussel. Ambos provenían del mismo lugar: Córdoba, Argentina, y ambos trabajaron y publicaron al mismo tiempo, a inicios de los años 1970.

La contribución de Levinas es muy importante porque da pié a una concepción fundamentada no en la unidad del ser, sino en la condición relacional fundamental para todo ser humano. No nacemos como individuos conscientes y capaces respecto de nosotros mismos; somos seres de relaciones en un mundo de relaciones (como ya decía Paulo Freire en los años 1960): nadie puede ser si no hay otros que, para bien o para mal, son con cada persona. Esto significa que el ser de la ontología no es un Uno, como se le ha considerado tradicionalmente, sino una díada. Se es junto con otros y no se puede ser si no hay otro. Levinas agrega a esa condición sine qua non, otra de carácter ético: la responsabilidad que todos tenemos a priori, por el otro (Levinas, 1974), y que es parte de la racionalidad de la razón. 
Esta inclusión del otro da lugar al concepto de alteridad (el concepto más importante en la psicología de la liberación y en toda psicología), fundamental en cualquier trabajo social, y que además es parte de la condición humana. Tanto, que todo lo que nos rodea es parte de la realidad histórica en la cual vivimos y que ha sido y es construida por personas en relación. Por eso, cuando segregamos a otros, cuando consideramos a determinadas categorías de personas superiores o inferiores que a otras, estamos apartando esa otredad, la cual, por no definirse como igual y con los mismos derechos, se excluye, define como diferente, inferior o incluso se elimina, por no ser como Uno.

El Otro ha sido visto como aquél que no es como uno, que es menos que el uno, y que por tanto está condenado a habitar los márgenes de la sociedad, a recibir los restos y las migajas y a quien se les rebajan los derechos, cuando no se les priva totalmente de ellos. El individuo no es la primera y última residencia del Ser. Es por esta razón que necesitamos trabajar para lograr una verdadera democracia en la cual la otredad no esté más allá de lo social positivo; es por eso que necesitamos generar métodos para la conciencia. Ya que es la conciencia la que nos permite darnos cuenta de los derechos y de su ausencia.

Enrique Dussel coloca las bases para un método filosófico que lleva a trabajar con el Otro, descubriendo en la otredad de los Otros la de nosotros mismos: la analéctica, un método que señala e incluye la alteridad u otredad en aquello que en la ontología y epistemología tradicional ha sido considerado como lo externo al núcleo que se entendía como propio del Uno, siempre central: es decir, de los muchos Unos que asumen el poder de dejar afuera, de cerrar o abrir la entrada hacia "su totalidad" solo a aquellos como él o ella, y no a los que califican como Otros, extraños, distintos. El ser reside y es, en la relación. La relación es lo que ocurre entre elementos que existen debido a la conexión que hay entre ellos. El sujeto se construye en la relación, a la vez que es parte activa de ella. La singularidad de la persona reside en su Otredad, la cual la hace diferente, diversa, externa.
La Otredad es la exterioridad. Una exterioridad que está fuera de la totalidad de quienes tienen el poder. Dussel entonces propone expandir la totalidad dialéctica, que viene de Aristóteles y que Hegel definió como el producto de un triángulo: el o los que proponen una tesis, el o los que cuestionan esa tesis proponiendo algo contrario a ella pero, por eso mismo, relacionado con ella: la antítesis y un tercer elemento, la síntesis que genera un nuevo conocimiento que parte de los dos anteriores. Dussel muestra que es necesario expandir la dialéctica incluyendo un cuarto elemento, la otredad, generando así la liberación del Otro, que no puede ni tiene lo que unos han considerado como lo que se debe ser y tener, pero que posee otros conocimientos, otra cultura, otras ideas.

\section{Presentar gráfico de totalidades}

Así, para Dussel, la otredad es el primer movimiento racional, previo a todo otro ejercicio de la razón, mediante el cual la experiencia o presencia actual del Otro se realiza antes de cualquier decisión, compromiso, comunicación o expresión lingüística relativa al Otro (Dussel, 1985). Y su propuesta es negar la negación producida por la exclusión, al rechazarla junto con la opresión. De esa manera, se puede construir un Yo y un Otro productores de conocimiento, unidos en relación. Relación que construye a ambos sujetos que a su vez la construyen, es decir, es la creación dialéctica de lo social. La singularidad está en la reciprocidad de cada parte, que la hace diferente, aunque igual en cuanto a su posibilidad de ser. La dimensión subjetiva es entonces recíproca y plural, a la vez que singular. El Yo no puede existir sin el Tú, puesto que para que ambos modos de ser, sean, es necesaria esa dualidad que une a la vez que distingue.

Es evidente que la igualdad de aquellos Otros considerados como distintos de los Nosotros, es el mayor problema de la humanidad. De las diferencias raciales, religiosas, de género y de ideas derivan guerras, segregación, opresión, exclusión. El método analéctico inicia con una concepción del mundo que 
nos dice que "el mundo es una totalidad instrumental de sentido"; no un agregado de seres, sino la totalidad de todos aquellos que tienen sentido para cada quien. $Y$ es en esa proximidad donde se va a generar la lejanía, que sirve de justificación a la exclusión de la Otredad, de aquellos para los cuales no tenemos sentido. Por eso la totalidad incluyente de la dialéctica dusseliana supone el paso de un horizonte a otro mayor, más despejado, lo cual supone un mundo en movimiento, cambiante, que fluye y se transforma con la inclusión.

Eso hace que la exterioridad sea la categoría más importante en la psicología de la liberación. El método del cual presentaré su técnica y su sentido busca expandir el horizonte de conocimiento incluyendo a personas pertenecientes a quienes son vistos como otros distintos y por lo tanto no pertenecientes a una visión específica del mundo predominante. $Y$ ello se hace a través de la praxis.

\section{Sobre la praxis}

Dado que me referiré a un método que proviene y aplica la praxis, es necesario definir qué se entiende por tal. Praxis es una práctica material que produce teoría y, a la vez, una teoría que genera modos de actuar en la práctica, generando conjuntamente un movimiento dialéctico. Se produce conocimiento en la acción reflexionada, conducente a su vez a la transformación de circunstancias sociales con incorporación de actores sociales comprometidos con esa transformación. Una primera condición es la de actuar con el otro, para lograr cambios tanto en la otredad de ese Otro excluido como en la otredad de los excluyentes, de los distintos de ellos. Como dice Dussel, al hablar de la praxis: es "un acercamiento a la proximidad" (Dussel, 1985, p.17). Al respecto señalo que Dussel piensa la praxis como algo que va del practicante hacia el Otro, cruzando el umbral del horizonte de la exterioridad. Pero eso no ocurre solo del lado de quien quiere liberar; ocurre también, inevitablemente, cuando ese Otro recibe y hace contacto con nosotros. Por eso, en el método analéctico la participación es fundamental; algo que, en su versión participativa

144 y liberadora, la PC latinoamericana conoce.

\section{Métodos para la conciencia; la analéctica en la acción}

La praxis que presentaré aquí se refiere a cuatro fenómenos que ocurren en la vida cotidiana y que, tanto en la PC y en la PL como en otras ramas de la psicología (social, clínica, ambiental, por ejemplo), son objeto de análisis y causa de problemas frecuentes en esta vida. Me refiero a la habituación, la naturalización, la ideologización y la alienación. Las trataré con el mismo método aunque esos aspectos no necesariamente responden de la misma manera, ni usan las mismas herramientas de la misma manera, ni actúan al unísono, si bien se relacionan entre sí. Los dos primeros, Habituación y Naturalización, pueden ser condiciones inocuas en la vida cotidiana; por su parte, y no obstante los dos segundos, Ideologización y Alienación, pueden tener sus bases en los dos primeros, hay factores externos que pueden generar profundos problemas en esa misma vida. Empezaré por los segundos.

\section{Ideologización y alienación: una reflexión tardía a tiempo}

Estos conceptos han transitado las ciencias sociales desde fines del siglo 19. De sus efectos en la vida social, las ciencias sociales nos han hablado y mucho, durante el siglo 20. Así, los primeros en señalar los efectos adversos sociales de la alienación fueron Marx y Engels, seguidos casi inmediatamente por sus primeros discípulos y a lo largo de todo el siglo 20 por marxistas, post marxistas y neomarxistas.

Inicialmente iba a empezar por colocar la definición de cada concepto y luego explicar cómo tratar cada uno por separado; momento en el cual pensé que, al llegar a la práctica, esta se haría redundante, puesto que, al usar la analéctica, estaba pasando de algo compartido desde la teoría a algo vivido en la cotidianeidad y producido en ella. No obstante, algo de los clásicos del siglo 20 nos será útil.

Fue Marx quien atribuyó a la alienación el sentido que aún perdura hasta nuestros días: sistema de ideas y representaciones que domina el 
espíritu de una persona o un grupo social, el cual genera consecuencias negativas. En el caso de la ideología, Althusser (1970) señaló por su parte que no hay ideologías específicas y que corresponde a una representación producida en la relación que existe entre la persona y sus condiciones de existencia, pues es en ellas donde reside la causa de la ideologización influida por "aparatos" materiales y por rituales de la vida social cotidiana vivida por las personas (Althusser, 1968/1980). No voy a volver a los debates del siglo 20, pero quiero citar una declaración de Althusser que me parece interesante para la psicología:

La relación vivida de los hombres con su mundo... no aparece como consciente sino a condición de ser inconsciente, de la misma manera, de la impresión de no ser simple sino a condición de ser compleja, de no ser una relación simple sino una relación de relaciones, una relación de segundo grado" (Althusser, 1968/1980, p.20).

Lo interesante aquí es el juego de la conciencia y de la inconsciencia. Y lo que estamos generando son métodos para la conciencia.

De esa forma, de ideología y alienación nos interesa el hecho de que, al tratar de aspectos sociales y políticos, estos afectan a las personas directamente a la vez que son producidos por ellas mismas en sociedad. La ideología y la alienación son construcciones humanas $y$, si bien desde una visión macrosocial se nos presentan como condiciones sociales que pueden abarcar a grandes masas y tener efectos en la estructura social, también actúan en cada individuo. Su raíz está en la mente y su poder reside en su apariencia social, propia de mucha gente. Al hacerse colectivo un determinado modo de interpretar al mundo y del que muchos se apropian, no se es consciente de su carácter externo e inducido. Pasa a ser social, a ser lo que se hace todos los días, y por lo tanto sólido y válido. La persona vive su alienación y actúa su ideología como parte de la vida corriente, haciendo lo que se hace como parte de la cotidianeidad. La fuerza de lo que hemos Ilamado ideología y alienación reside en vivir la vida de una manera considerada como el modo normal, habitual y natural de vivir, sin conocer el origen de ese modo, a quiénes favorece y a quiénes perjudica, y por qué.

\section{Sobre desideologización y desalienación}

Lo contrario de ideologizar y alienar es desideologizar y desalienar. Se define desideologizar como la reconstrucción o construcción de una consciencia integral no fraccionada mediante la cual se produce una comprensión del mundo en el que se vive y de las circunstancias de la vida, como un todo. Implica un proceso de producción de conocimiento conducente a establecer causas y conexiones, disipando la ignorancia necesaria para mantener un cierto estado de cosas, al desarrollar una conciencia diferente (Montero, 2004).

Desalienación es el proceso mediante el cual la relación entre la conciencia y las condiciones históricas y sociales de la vida de las personas, tras ser analizadas a fin de conocer y comprender el modo como han sido establecidas sus relaciones en esa vida, generan en el sujeto no solo la consciencia de sí, de la situación y de sus causas, sino que inducen asimismo a producir nuevas formas de vida y de acción; es decir, este utiliza la praxis para movilizar la consciencia.

Como se puedever, cualquiera de los conceptos podría ser la base del otro. Asimismo, y al igual que los otros dos conceptos objeto de esta conferencia (habituación y naturalización), pueden indicar el modo en que los recientemente mencionados producen sus efectos en las personas.

\section{Sobre habituación y naturalización}

Habituación y naturalización son dos procesos vividos sin pensar, pues son parte de la vida diaria, además de ser necesarios para poder vivir. La vida cotidiana es una red de relaciones en las cuales se insertan y elaboran estos procesos usuales, aparentemente sin nada que ver con la ciencia, su práctica y su conocimiento. De la habituación, Pierre Bourdieu (1972) nos ha dado una óptima definición 
señalando sus elementos. Bourdieu parte de la noción de habitus, es decir hábito: un comportamiento estructurado y estructurador que no se discute ni se asume conscientemente, pero que produce patrones sistemáticos ajustados a los ya existentes y que se adapta a las regulaciones colectivas de una sociedad sin necesidad de instrucciones específicas, por lo cual constituye una respuesta social codificada y esperada, carente de intenciones estratégicas, ya que permite a las personas encarar diversas situaciones. El hábito se anticipa a las consecuencias de esas situaciones y tiende a reproducir las estructuras sociales existentes, manteniéndolas (Tabla 1).

La base de la habituación reside en las conductas cotidianas y se define como un comportamiento diario y maquinal, que no se piensa ni se planifica y que se hace de manera casi automática. La habituación incorpora patrones sociales y culturales implícitos así como expectativas sociales, facilitando la vida social al liberarla de la necesidad de pensar y planificar los actos cotidianos, teniendo que reflexionar y tomar decisiones. Esto que parece tan cómodo puede, sin embargo, llevar a las personas, en determinadas circunstancias, a comprometerse sin darse cuenta en situaciones irreflexivas, acríticas y perjudiciales para ellas.
Ciertamente, si tuviésemos que pensar muchos de nuestros actos habituales perderíamos un tiempo considerable vacilando entre diversas opciones o decidiendo qué hacer; pero, al mismo tiempo, hay momentos en los cuales es necesario tomar nuevas decisiones, usar otras palabras, ejecutar acciones distintas necesarias para nuestras vidas y las de otras personas. Si nuestra alienación es tan profunda o tan amplia que no nos permita ver lo dudoso, peligroso, negativo o injusto de ciertas acciones e ideas, somos víctimas de esas circunstancias alienantes. La alienación, como la ideología, al convertirse en hechos de la vida cotidiana, tiene en la habituación y la naturalización dos modos que le permiten expandir ideas y acciones negativas para las personas y su entorno.

La naturalización, que puede a su vez ser causa y ayuda de la habituación, se define como el proceso social mediante el cual ciertos fenómenos o patrones de conducta vienen considerados como el modo esencial de ser de las cosas, proceso fundamentado en razones ligadas a la cultura y la historia y, con ellas, a las distinciones de clase, de género, religión y tradición como creencias derivadas de situaciones creadas a partir de estos aspectos. Es decir, son tales como las percibimos y creemos que ellas son, en determinados momentos,

\section{Tabla 1}

Bases de la habituación

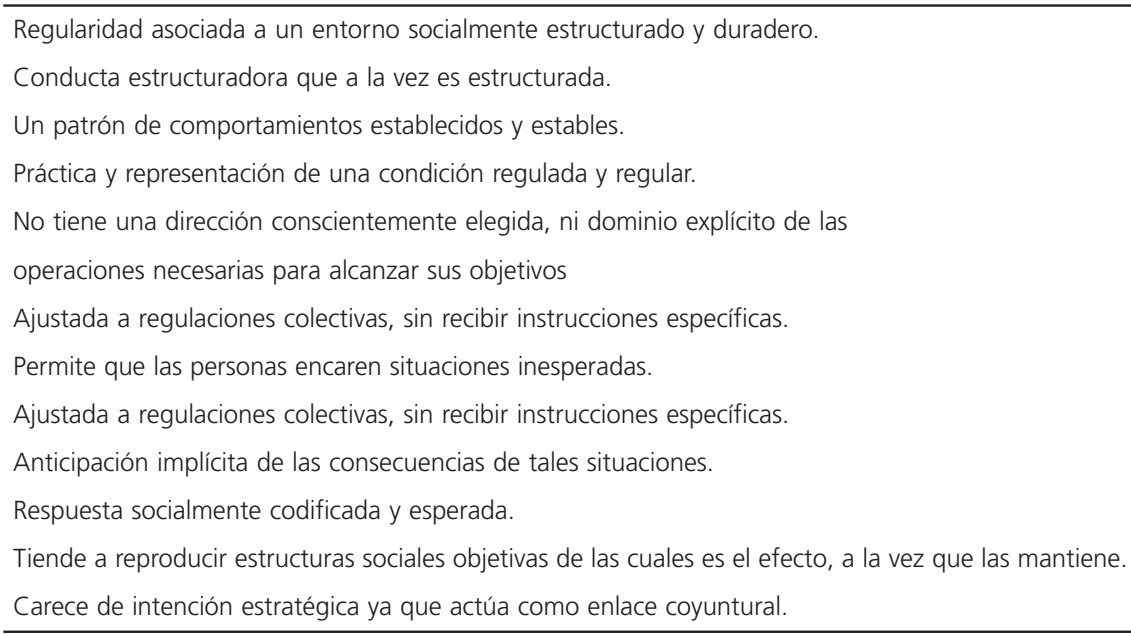

146

Fuente: Pierre Bourdieu (1972). 
o a lo largo de nuestras vidas. La naturalización lleva a creer que tales prácticas y creencias son parte esencial de la naturaleza de la sociedad y del mundo en general, y por lo tanto se las defiende y pueden ser difíciles de cambiar. Ese proceso mantiene y también facilita la vida cotidiana, la cual a su vez lo fortalece. Asimismo, es responsable de la aceptación de aspectos negativos por parte de las personas, que pueden dificultar e incluso volver insoportables ciertas situaciones para ellas o para grupos.

La desnaturalización, el proceso para lograr que algo naturalizado sea comprendido en su condición y origen, es un examen crítico de aquellas creencias y procedimientos que sustentan los modos de hacer y comprender la vida cotidiana, de modo que lo que ha sido naturalizado sea desprovisto de su "naturalidad" atribuida, mostrando así su carácter construido. Ella se inicia al problematizar el aspecto esencial y natural adjudicado a ciertos hechos y relaciones, revelando sus contradicciones, así como también su vinculación con intereses sociales o políticos (Montero, 2004), para lo cual es necesario utilizar ejemplos contrastantes que obliguen a pensar en las contradicciones, no por imposición de los agentes externos, sino en un proceso que ocurrirá en la mente de la persona.

Nuevamente vemos en este proceso, complementario del anterior, cómo la ideología y la alienación pueden ser parte de lo habitual y naturalizado, produciéndose en el nivel individual, ya que ocurren en cada persona de acuerdo con sus características personales. Y vemos cómo eso sucede a la vez a nivel social, puesto que se naturalizan prácticas que son aceptadas, copiadas, inducidas y a veces impuestas, hasta que las víctimas las apropian (a la vez que ellas mismas son apropiadas por estos fenómenos).

Los cuatro procesos cuyo método específico presento, así como el posible resultado del mismo, pueden llevar a la concientización, y tienen en su base por su vez un proceso cuyo método ya he presentado en ocasiones anteriores: la problematización (Montero, 2006; 2007; 2009). La problematización es el punto de partida para el inicio del cuestionamiento de ideas y de modos de ser, pensar, vivir y actuar. Problematizar es movilizar la conciencia de la conciencia. Su praxis consiste en "plantear situaciones que llevan a las personas a revisar sus acciones y opiniones acerca de acontecimientos habituales de su vida" (situaciones y hechos), que son percibidos como "inevitables o esenciales para el ser de esas cosas" (Montero, 2009, p.80). La problematización es parte de la construcción de una conciencia crítica producida simultáneamente por la acción y la reflexión, por lo que ella necesita tanto desnaturalizar como romper con prácticas habituales, al conocer sus orígenes y efectos alienantes. Por eso es necesario generar una praxis que deshabitúe, desnaturalice, desideologice y desaliene, como submétodos del proceso problematizador, que conduzca a la concientización. Si bien este último proceso es iterativo y abarca todos los anteriores, cada uno de ellos puede generar prácticas específicas según las situaciones.

\section{Un método analéctico para obtener una praxis liberadora por la vía de la transformación desde el sujeto}

Para trabajar sobre habituación, naturalización, alienación e ideología necesitamos estar conscientes de su existencia y sus efectos negativos sobre las personas - tales como considerar que no son capaces de aprender o modificar un tipo de acción que resulta peligroso, negativo o inútil para ellas, o bien que, por ser quienes son, nunca lograrán cambiar de posición ni de modificar su mundo-devida -, y de que se trata de un trabajo que debe realizar la propia persona que vive la situación. Nuestra tarea es facilitar esa transformación, la cual será ejecutada por cada persona según su ritmo y a su manera, y con mayor o menor rapidez o lentitud. Presionar es contraproducente. $Y$ pensar que un grupo, al unísono, logrará los mismos resultados, es una ilusión que puede llevar a efectos negativos (aburrimiento y/o suspicacia por parte de las personas con las cuales se trabaja).

Sin embargo, cuando una o varias personas de un grupo son conscientes de que lo que han creído como imposible es posible al abandonar ciertas prácticas o cambiar de ideas, ellas mismas se convierten en agentes de cambio con sus acciones y sus palabras. No obstante, indefectiblemente, cada persona tiene su propio ritmo. 
Generalmente las personas se aferran a aquello que han conocido como "el modo de ser de las cosas", por lo cual la mejor manera de iniciar un diálogo que logre una apertura hacia otra realidad no es la contradicción, ni la burla, ni la degradación de la opinión del otro. Como ya he dicho en otras ocasiones (Montero, 2007; 2009), el mejor método es la mayéutica (el método socrático). Es decir, las preguntas que confrontan una idea establecida con una realidad diferente y que llevan a pensar en la contradicción desde la posición misma de la persona.

Un segundo aspecto es que no deben esperarse inmediatamente una respuesta desalienada o desideologizada; el hábito advertido como tal y la sinrazón de su existencia, o el darse cuenta de que ciertas prácticas e ideas no son para nada naturales. Las personas reflexionan y eso puede llevar tiempo, aunque es posible ayudarlas mediante prácticas tales como las preguntas problematizadoras, que son aquellas en las cuales se pregunta si hay algo que está ocurriendo, o considerar sus efectos como buenos o malos o justos o injustos y, luego de oír las respuestas - si éstas son afirmativas y a la vez presentan aspectos negativos; o no se sabe por qué ese algo se da, o debe ser parte de sus vidas -, continuar indagando hasta que no haya ninguna razón para que eso exista o tenga que observarse, o esté en las vidas de las personas. Cuando se produce un silencio y no hay más explicaciones para el uso, comienzan a aparecer las preguntas y observaciones provenientes de los cambios en cada consciencia.

También es posible utilizar otros métodos auxiliares como la dramatización o la creación colectiva de un cuento alusivo a una situación problemática y a la vez considerada como básica en la vida de la gente. La dramatización es una representación alegórica y la posterior discusión e interpretación de lo dicho o representado. El guión de la representación debe ser trabajado con mucho cuidado y debería surgir de situaciones específicas de cada grupo, de tal manera que las personas puedan reconocer, en la obra teatral, lo que pasa en sus vidas. La separación entre la escena y el público permite una distancia en la cual es posible reconocerse y a la vez hablarle al personaje, y los 148 personajes pueden mostrar lo que no se ve en la vida cotidiana. Los ejemplos cercanos y sus soluciones o sus dificultades para ser solucionados también son útiles, así como el análisis de contrastes entre dos situaciones.

Sintetizando, las características de estos métodos son las siguientes:

1. Quienes vayan a trabajar con la analéctica, necesitan conocer muy bien el ambiente y el o los grupos con los cuales se va a realizar la praxis.

2. La condición básica es trabajar con las personas, y no para ellas desde fuera de su círculo.

3. En su condición mayéutica, es necesario estar atento a lo que se dice y cómo se lo dice, a fin de crear, en función de lo oído y visto, las preguntas y/o situaciones que estimulen la movilización de la consciencia en relación con un hecho, caso o situación.

4. El agente externo ayuda a generar las situaciones contrastantes, pero no las impone. Es necesaria una situación participativa y de confianza en la cual agentes internos y externos están interesados. La psicóloga hace su pregunta o comentario a partir de lo que se dice en el grupo. La dirige a la persona que ha dicho algo, si bien cualquier persona del grupo puede responder $\mathrm{o}$ complementar lo que se está diciendo.

5. Si ante cada pregunta problematizadora hay una respuesta defensiva, un modo sencillo que sin embargo solo debe utilizarse según las circunstancias -, es el de preguntar "¿Por qué?" sucesivamente, hasta que se haga el silencio.

6. El silencio producido por la ausencia de razones sustentadoras de algún hábito, naturalización o creencia, debe ser seguido de una invitación a buscar nuevas pruebas o ejemplos diferentes, y reflexionar sobre ellos.

7. La contradicción debe ser cuestionadora (¿por qué?) pero no persecutoria. Hay que dejar tiempo a la conciencia de cada quien.

8. También se pueden presentar preguntas a un grupo para que las piensen y luego, en otra reunión, o más tarde, se reflexione en grupo sobre ellas. Las preguntas deben ser concernientes a lo que el grupo o una persona está trabajando o diciendo. 
9. La tarea de los agentes externos exige de estos una gran atención, ya que sus preguntas o ejemplos a contrastar deben surgir al momento, según el clima del grupo y en función de sus intereses.

10. En todos estos procesos, siempre es necesario hacer un resumen al final de la acción o tarea, indicando qué se logró, qué estuvo bien hecho o pensado haciendo tal cosa. Ese cierre no necesariamente debe realizarlo el agente externo, sino como cierre propio del grupo.

11. Todos los métodos para la conciencia hasta ahora creados son también métodos participativos. Todos, además, llevan a la concientización.

\section{Conclusión}

Las circunstancias ideologizadoras y alienantes, así como las habituales y todas las fórmulas que las representan, al igual que lo que se considera como obvio y natural, no se abandonan rápidamente. Por lo tanto, los ejemplos que se presentan deben surgir en los grupos y venir al caso. Asimismo, todas las personas que participan, internas y externas, deben estar conscientes de sus propios sesgos y tendencias y no utilizar su relación con las personas con las cuales se trabaja para influir en función de sus creencias. Eso podría contribuir a mantener aquello que se supone que deberían ayudar a superar.

He trabajado sobre conceptos que responden a hechos que son parte de la vida cotidiana y cuyas bases también están en esa vida y en su carácter político-social; sin embargo, hay más conceptos y situaciones de ese tipo: por ejemplo la dehistorización, que consiste en la manipulación de los hechos históricos para presentarlos positiva o negativamente a favor de determinados grupos e ideas; o la despolitización, que induce a considerar que la política es asunto de los políticos de profesión (usualmente así autodenominados) y no de los ciudadanos. La conciencia es el campo de batalla de la liberación, porque es ella la que conduce a la libertad, al conocimiento y al autoconocimiento y es para ella, en cada persona y grupo, que la Psicología debe trabajar.

Los agentes internos o externos, ya sea en el trabajo comunitario o en intervenciones de orden social, deberán partir de una base ética, cuya expresión es el respeto del otro. En tal sentido, deben indicar por qué, para qué, para quién o quiénes están allí, y entender que las acciones a cumplir deben generarse desde la participación y no desde la imposición.

\section{Referencias}

Althusser, L. (1980). Polémica sobre marxismo y humanismo. In L. Althusser, J. Semprun, M. Simón, \& M. Verret (Coords.), Marxismo y humanismo (pp.34-48). México: Siglo XXI. (Publicado originalmente en 1968).

Althusser, L. (1970). Ideología y aparatos ideológicos del Estado. Medellín: Ediciones PEPE.

Bourdieu, P. (1972). Esquisse pour une theorie de la pratique. Ginebra: Droz.

Dussel, E. (1985). Philosophy of liberation. Eugene: Wipf \& Stock.

Levinas, E. (1995). Totalidad de infinito. Salamanca: Sígueme. (Publicado originalmente en 1970).

Levinas, E. (1974). Autrement qu'être ou au-delà de I'essence. La Haya: Martinus Nijhoff.

Montero, M. (2004). Introducción a la psicología comunitaria. Buenos Aires: Paidós.

Montero, M. (2006). Hacer para transformar: el método en la psicología comunitaria. Buenos Aires: Paidós.

Montero, M. (2007). La problematización como aspecto crítico en el proceso de liberación. In I. Dobles Oropeza, S. Baltodano Arroliga, \& V. Leandro Zúñiga (Eds.), Psicología de la Liberación en el contexto de la globalización neoliberal (pp.216-229). San José: Universidad de Costa Rica.

Montero, M. (2009). Method for liberation: critical consciousness in action. In M. Montero \& C. Sonn (Eds.), Psychology of liberation (pp.73-92). Nueva York: Springer.

Recibido: enero 24, 2014

Versión final: abril 11, 2014

Aprobado: abril 28, 2014 
